\title{
IDENTIFICATION OF NURSE KNOWLEDGE AND ATTITUDE TOWARDS PALLIATIVE CARE IN RSUD Dr. M. YUNUS BENGKULU
}

\author{
Qurratul A'yuni ${ }^{1}$, Tuti Anggriani Utama (Correspondence) ${ }^{2}$, Maiyulis ${ }^{3}$ \\ ${ }^{1,2,3}$ Universitas Bengkulu
}

Email Correspondence: tutiutama12@gmail.com

\begin{abstract}
This study aims to identify the knowledge and attitudes of nurses towards palliative care in Dr. M. Yunus Bengkulu. The type and research method used is descriptive quantitative with a cross sectional study. The research subjects were 63 nurses in the Intensive Care Unit (ICU), the Intensive Coronary Care Unit (ICCU), the Seruni Room and the Hemodialysis Room (HD) at Dr. M. Yunus Bengkulu. Data collection techniques using a questionnaire (Questionnaire). The data analysis technique used the Univariate technique. There are 3 types of data processing techniques, namely; Editing, Coding, and Scoring. The validity test for the Knowledge level questionnaire used the The Palliative Care Quiz for Nurses- Indonesian (PCQN-I) questionnaire while for attitudes the Frommelt's Attitude Toward Care of The Dying Care Form B (FATCOD-B) questionnaire was used to measure knowledge. with a result of 0.71 (Kuder-Richardson Formula Score) while to measure attitudes the result is 0.68 (Alpha Cronbach). The results showed that the nurses studied in 4 rooms in RSUD M. Yunus Bengkulu were mostly female, namely $65 \%$, then the latest education of nurses was $48 \%$, the majority were Ners and $60,3 \%$, the nurses studied were average -the average age $\geq 35-50$. The results obtained the knowledge and attitude value of 63 nurses in 4 rooms of RSUD Dr. M. Yunus Bengkulu as many as $52 \%$ of respondents have less knowledge and most of the respondents have a negative attitude towards palliative care.. It can be concluded that the nurses studied have less knowledge and attitudes towards palliative care.
\end{abstract}

Keywords: attitude, knowledge, characteristics, nurses

\section{PENDAHULUAN}

Perawatan paliatif merupakan perawatan total yang diberikan kepada pasien dan keluarga pasien yang menderita penyakit yang membatasi hidup yang dilakukan oleh tim secara interdisiplin, dimana penyakit pasien tersebut tidak dapat lagi berespon terhadap pengobatan atau pasien yang tidak mendapatkan intervensi 
untuk memper-panjang masa hidup (Yodang, 2018). Hal ini dapat disimpulkan bahwa perawatan paliatif diberikan kepada pasien yang memiliki riwayat penyakit yang secara medis tidak dapat disembuhkan.

Menurut WHO dalam (Agustina, 2019) bahwa ada 40 milyar orang di dunia yang membutuhkan perawatan paliatif, diantaranya mereka yang menderita penyakit kronis seperti penyakit kardiovaskular (38,5\%), kanker (34\%), penyakit paru kronis $(10,3 \%)$, AIDS (5,7\%) dan diabetes (4,6\%). Hal ini ditekankan kembali menurut WHO dalam (Veronica, 2018) bahwa perawatan paliatif bukan hanya untuk pasien yang memiliki riwayat penyakit kanker saja. Ini juga untuk pasien dengan penyakit degeneratif, penyakit paru obstruktif, fibrosis kistik, stroke, Parkinson, gagal jantung, penyakit genetik dan penyakit menular seperti HIV / AIDS. (Agustina, 2019) menyatakan bahwa tujuan perawatan paliatif untuk meningkatkan kualitas hidup pasien di akhir kehidupanya serta bersama-sama memberikan perawatan yang lengkap dan sebaik-baiknya. Dari hasil pengamatan ditemukan beberapa permasalahan perawatan paliatif di antaranya : (1) kurangnya pengetahuan tentang perawatan paliatif, (2) belum optimalnya menerap-kan sikap yang baik dalam perawatan paliatif. Melihat permasalahan yang seperti ini, pengetahuan dan sikap seorang perawat harus diterapkan dalam memberikan perawatan paliatif.

Pengetahuan dan sikap perawat juga diperlukan dalam mengkaji dan mengevaluasi keluhan pasien. Perawat dengan anggota tim berbagai keilmuan dapat mengembangkan dan mengim-plementasikan rencana perawatan secara menyeluruh untuk meningkatkan kualitas hidup pasien. (Maulida, dkk, 2017) mengemukakan bahwa pengetahuan dan sikap sangat penting ditunjukkan oleh seorang perawat ketika akan memberikan asuhan keperawatan terhadap perawatan paliatif. Perawat harus memberikan perawatan yang bisa diberikan kepada pasien, baik kebutu-han fisik, psikologis ataupun spiritual. Menurut (Natoatmodjo, 2014), pengetahuan sangat penting untuk terbentuknya tindakan serta memiliki beberapa tingkatan pengetahuan di antaranya, tahu (know), memahami (comprehension) 
dan aplikasi (application). Sikap seorang perawat juga merupakan hal yang penting dalam perawatan paliatif. Menurut (Wawan \& Dewi, 2019), bahwa sikap terdiri dari 4 tingkatan yaitu dapat menerima (receiving), mampu merespon (responding), dan menghargai (valuing) serta bertanggung jawab (responsible).

Sikap dalam perawatan paliatif dapat menjadikan tolak ukur efektifnya proses pembelajaran atau pelatihan. Indikator yang dimaksud adalah mencakup kognitif, afektif, dan psikomotor (Hafifah, 2018). Hasil studi menyebutkan bahwa sikap yang positif dalam perawatan paliatif dapat menjadi tolak ukur keberhasilan mahasiswa keperawatan terhadap pasien menjelang ajal (Grubb \& Arthur dalam Zulfatul, 2016). Selain itu dijelaskan lagi oleh Grubb \& Arthur dalam (zulfatul, 2016), bahwa sikap perawat yang negatif, seperti perasaan tidak peduli, takut, dan cemas dalam setiap pemberian asuhan keperawatan dapat menurunkan kualitas pelayanan menjelang ajal pada pasien. Untuk mengatasi hambatan tersebut, peneliti bermaksud ingin mengindentifikasi pengetahuan dan sikap perawat terhadap perawatan paliatif pada pasien di RSUD Dr. M. Yunus Bengkulu. Adapun tujuan dari penellitian ini ialah untuk Mengidentifikasi Pengetahuan dan Sikap Perawat Terhadap Perawatan Paliatif di RSUD Dr. M. Yunus Bengkulu. Selain itu tujuan penelitian ini ialah Mengidentifikasi gambaran karakteristik perawat (usia, jenis kelamin, pendidikan terakhir) di RSUD Dr. M. Yunus Bengkulu.

\section{METODE}

Jenis penelitian yang dilakukan ini adalah deskriptif kuantitatif dengan studi cross sectional. Jumlah Populasi dalam penelitian ini adalah 63 perawat di RSUD Dr. M. Yunus Bengkulu dengan menggu-nakan teknik Sampling Total. Penelitian ini dilaksanakan pada Ruang Intensive Care Unit (ICU), Ruang Intensive Coronary Care Unit (ICCU), Ruang Kemoterapi dan Ruang Hemodialisa (HD) di Rumah Sakit Umum Daerah (RSUD) Dr. M. Yunus Bengkulu pada bulan Februari Maret tahun 2021. 
Untuk mengukur tingkat pengetahuan mahasiswa tentang keperawatan paliatif digunakan kuesioner The Palliative Care Quiz for Nursing (PCQN) yang terdiri dari 20 pertanyaan dengan pilihan jawaban "Benar" dan Salah", "Benar" diberi skor 1 dan "Salah" diberi slor 0. Sedangkan untuk mengukur sikap mahasiswa digunakan kuesioner The Frommelt's Attitude Toward Care of The Dying Care Form B (FATCOD-B) Versi Bahasa Indonesia yang terdiri dari 30 pertanyaan menggunakan skala Likert. Analisi data menggunakan chi-square.

\section{HASIL}

Tabel 1 Distribusi frekuensi jumlah keseluruhan perawat berdasarkan jenis kelamin di RSUD Dr. M.Yunus Bengkulu $(\mathbf{n}=63)$

\begin{tabular}{ccc}
\hline Jenis kelamin & Frekuensi & Persentase \\
\hline Laki-laki & 22 orang & $35 \%$ \\
Perempuan & 41 orang & $65 \%$ \\
\hline Total & $\mathbf{6 3}$ orang & $\mathbf{1 0 0 \%}$ \\
\hline
\end{tabular}

Dari tabel 1 di atas dapat dilihat bahwa sebagian besar responden yang diteliti berjenis kelamin perempuan yaitu sebanyak 41 orang (65\%), sedangkan responden yang berjenis kelamin laki-laki hanya 22 orang (35\%).

Tabel 2 Jumlah keseluruhan perawat berdasarkan pendidikan di RSUD Dr.M.Yunus Bengkulu $\quad(n=63)$

\begin{tabular}{ccc}
\hline Pendidikan Terakhir & Frekuensi & Persentase \\
\hline D3 & 12 orang & $19 \%$ \\
S1 & 21 orang & $33 \%$ \\
Ners & 30 orang & $48 \%$ \\
\hline Total & 63 orang & $\mathbf{1 0 0 \%}$ \\
\hline
\end{tabular}

Dari Tabel 2 di atas dapat dilihat bahwa sebagian besar pendidikan yang ditempuh oleh responden adalah Ners yaitu sebanyak 30 orang (48\%), sedangkan responden yang tamatan S1 sebanyak 21 orang (33\%). Adapun perawat yang tamat pendidikan D3 berjumlah 12 orang (19\%). 
Tabel 3 Distribusi frekuensi berdasarkan kategori umur para perawat yang bekerja di RSUD Dr. M. Yunus Bengkulu $(n=63)$

\begin{tabular}{ccc}
\hline Umur & Frekuensi & Persentase \\
\hline$\leq 25-35$ thn & 25 orang & $39,7 \%$ \\
$\geq 35-50$ thn & 38 orang & $60,3 \%$ \\
Di atas 50 thn & - & - \\
\hline Total & 63 orang & $\mathbf{1 0 0 \%}$ \\
\hline
\end{tabular}

Dari Tabel 3 di atas dapat dilihat bahwa sebagian besar perawat yang bekerja di RSUD Dr. M.Yunus Bengkulu berumur $\geq 35$ - 50 thn yakni sebanyak 38 orang $(60,3 \%)$, sedangkan yang berumur $\leq 25-35$ thn sebanyak 25 orang $(39,7 \%)$.

Tabel 4 Frekuensi Pengetahuan Perawat terhadap Perawatan Paliatif pada Pasien di RSUD Dr. M. Yunus Bengkulu (n= 63)

\begin{tabular}{cccc}
\hline Pengetahuan perawat & Frekuensi & Persentase \\
\cline { 1 - 1 } Baik & 6 & $10 \%$ \\
Kukup & 24 & $38 \%$ \\
Total & 33 & $52 \%$ \\
& $\mathbf{6 8}$ & $\mathbf{1 0 0 \%}$
\end{tabular}

Dari tabel 4 di atas diperoleh hasil bahwa pengetahuan perawat terhadap perawatan paliatif pada pasien secara keseluruhan yang ada di 4 ruangan RSUD Dr. M. Yunus Bengkulu sebanyak 52\% masih berpengetahuan kurang dan sebanyak $10 \%$ yang berpengetahuan baik. Hal ini dapat disimpulkan sebagian besar pengetahuan perawat terhadap perawatan paliatif pada pasien yang ada di RSUD Dr. M. Yunus masih kurang.

Tabel 5 Distribusi Nilai Sikap Favourable-Unfavourable Perawat Terhadap Perawatan Paliatif Pada Perawat Di RSUD Dr. M.Yunus Bengkulu $(n=63)$

\begin{tabular}{|c|c|c|c|c|}
\hline \multicolumn{5}{|c|}{ FAVOURABLE - UNFAVOURABLE } \\
\hline SKOR & & $\mathrm{x}(\mathrm{X}-\mathrm{M})$ & $\mathrm{x} 2$ & $\mathbf{T}$ \\
\hline STS & 313 & -65 & 4225 & 23,86409 \\
\hline TS & 765 & 387 & 149769 & 205,6092 \\
\hline RR & 238 & -140 & 19600 & $-6,29272$ \\
\hline $\mathrm{S}$ & 435 & 57 & 3249 & 72,91918 \\
\hline SS & 139 & -239 & 57121 & $-46,0997$ \\
\hline TOTAL & 1890 & & 233964 & 250 \\
\hline
\end{tabular}




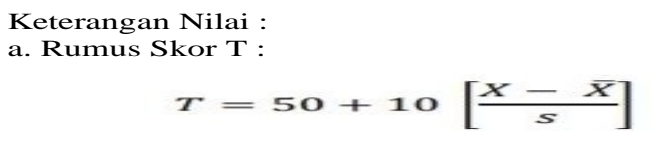

$$
T=50+10\left[\frac{x-\bar{x}}{s}\right]
$$

b. Rumus Mean

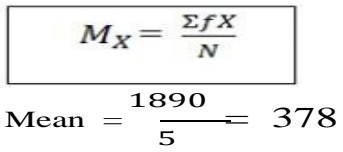

c. Rumus Standar Deviasi

$$
\begin{aligned}
& S L D=\sqrt{\frac{\sum x^{2}}{N}} \\
& \text { Standar Deviasi }=\frac{\sqrt{888}}{378} \\
&=\sqrt{618,9524}=24,87
\end{aligned}
$$

Keterangan :

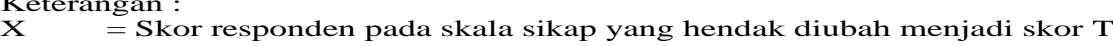
= Mean skor kelompok

= Deviasi standar skor kelompok

Pada tabel 5 di atas menggambarkan bahwa hasil dari nilai sikap Favourable - Unfavourable 63 perawat terhadap perawatan paliatif yang ada pada 4 ruangan di RSUD Dr. M. Yunus Bengkulu bersikap negatif atau tidak mendukung dengan hasil Nilai Mean yang didapatkan dari data sebesar 378 sedangkan total T yang diperoleh sebesar 250.. Dikatakan nilai Positif jika skor T $>$ nilai mean, sedangkan nilai Negatif jika skor $\mathrm{T}<$ nilai mean (Azwar,2011). Hal ini dapat disimpulkan sebagian besar sikap perawat terhadap perawatan paliatif pada pasien yang ada di RSUD Dr. M. Yunus memiliki nilai sikap negatif atau tidak mendukung.

\section{PEMBAHASAN}

\section{a. Gambaran Karakteristik Perawat di RSUD Dr. M. Yunus Bengkulu}

\section{Jenis Kelamin}

Hasil penelitian yang telah dilakukan di 4 ruangan RSUD Dr. M. Yunus Bengkulu menggambarkan bahwa sebagian besar responden berjenis kelamin perempuan yakni berjumlah 41 orang (65\%), dan responden laki-laki hanya berjumlah 22 orang (35\%). Disini dapat terlihat bahwa jumlah perawat perempuan lebih banyak dibandingkan dengan perawat laki-laki. Menurut beberapa peneliti hal ini terjadi karena perempuan memiliki daya tarik yang tinggi untuk menjadi seorang perawat daripada laki-laki. Hal ini sejalan dengan hasil penelitian Chover- Sierra (2017) yang menunjukkan bahwa perawat perempuan lebih banyak dibandingkan perawat laki laki. Perbedaan proporsi antara perawat laki-laki dan perempuan bisa 
saja disebabkan karena laki-laki memiliki minat yang kurang dalam bidang keperawatan dibanding perempuan.

\section{Pendidikan Terakhir}

Hasil penelitian yang telah dilakukan menggambarkan bahwa responden yang diteliti lebih banyak lulusan Ners yaitu sebanyak 30 orang (48\%), sedangkan yang paling sedikit adalah lulusan D3 ada 12 orang (19\%). Menurut beberapa peneliti hal ini dapat terjadi karena seseorang mempunyai pemikiran bahwasanya semakin tinggi pendidikan semakin banyak pengetahuan serta keterampilan yang dimiliki dan dikuasai oleh seseorang. Hal ini dikuatkan oleh hasil penelitian SumarniUtami-Elita (2020) yang menyatakan bahwa sebagian besar responden mayoritas berpendidikan DIII Keperawatan, dengan pendidikan yang tinggi maka dapat mempengaruhi tingkat pengetahuan seseorang dalam berbagai hal. Dijelaskan kembali oleh Kemenkes RI (2015), kriteria perawat yang memberikan perawatan paliatif adalah perawat yang berpendidikan minimal Diploma 3 dan telah mengikuti pelatihan perawatan paliatif.

\section{Umur}

Hasil penelitian yang telah dilakukan menggambarkan bahwa sebagian besar responden yang melakukan asuhan perawatan paliatif di RSUD Dr. M.Yunus Bengkulu berumur $\geq 35-50$ thn yakni sebanyak 38 orang $(60,3 \%)$, sedangkan yang berumur $\leq 25-35$ thn sebanyak 25 orang $(39,7 \%)$. Hal ini sejalan dengan hasil penelitian Fitri-Natosba-Andhini (2016) yang menyatakan bahwa pengetahuan responden yang baik tentang perawatan paliatif dipengaruhi juga oleh faktor lain, yaitu usia responden yang berada dalam kategori usia produktif. Perawat dengan usia muda merupakan perawat yang sedang berada pada tahap perkembangan generativitas, yaitu suatu tahap dimana perawat akan memperhatikan ide dan memiliki rasa ingin tahu tentang pengetahuan baru dan meningkatkan kreativitas yang dimilikinya. 


\section{b. Tingkat Pengetahuan Perawat terhadap Perawatan Paliatif di RSUD Dr. M. Yunus Bengkulu}

Pada penelitian yang telah dilakukan di RSUD Dr. M. Yunus tentang pengetahuan perawat terhadap perawatan paliatif didapatkan hasil bahwa sebagian besar responden yang diteliti sebanyak 52\% memiliki tingkat pengetahuan yang masih kurang dengan rentang skor 0-11 dan sebanyak 10\% memiliki tingkat pengetahuan yang baik dengan rentang skor 16-20. Penelitian ini dilakukan terhadap 63 responden yang ada pada 4 ruangan di RSUD Dr. M. Yunus Bengkulu. Ada 20 butir pertanyaan untuk mengetahui tingkat pengetahuan perawat terhadap perawatan paliatif dengan menggunakan kuesioner The Palliative Care Quiz for Nursing (PCQN) yang memakai Skala Guttman. Menurut Sugiyono (2016), skala Guttman akan mendapatkan jawaban yang tegas terhadap suatu permasalahan yang ditanyakan, yaitu "benar dan salah". Hasil penelitian yang telah dilakukan sejalan dengan (Siagian \& Perangin-angin, 2020) yang mengatakan bahwa hasil penelitiannya menunjukan bahwa 99,17\% responden mempunyai tingkat pengetahuan yang rendah. Hal ini berbanding terbalik dengan hasil penelitian Faidah Y. (2018) bahwa dari 98 responden sebagian besar perawat memiliki tingkat pengetahuan cukup sebanyak 53 perawat $(54.1 \%)$ dengan rentang skor 12-15, dan sebanyak 45 perawat memiliki tingkat pengetahuan kurang (45.9\%) dengan rentang skor 0-11. Sama halnya dengan penelitian Indarwati (2019) yang mengatakan bahwa perawat memiliki keterbatasan mengenai pengetahuan tentang perawatan paliatif sehingga pemberian pelayanan perawatan paliatif menjadi kurang maksimal.

Berdasarkan beberapa pendapat di atas diperoleh hasil yang berbeda dengan penelitian yang saya lakukan. Penelitian yang saya lakukan sebagian besar pengetahuan respondennya terhadap perawatan paliatif masih kurang sejalan dengan penelitian Siagian \& Perangin-angin (2020) bahwa responden yang ditelitinya pengetahuannya masih rendah. Perbedaan hasil penelitian itu terjadi dikarenakan tingkat pengetahuan seseorang yang berbeda. Sebagian besar responden yang saya teliti adalah lulusan Ners, hal ini juga dapat mempengaruhi 
pengetahuannya. Sebaiknya dilakukan pelatihan-pelatihan khusus perawatan paliatif agar para perawat yang bertugas dapat mengembangkan ilmu pengetahuannya.

\section{Gambaran Sikap Perawat terhadap Perawatan Paliatif di RSUD Dr. M. Yunus Bengkulu}

Hasil penelitian yang telah dilakukan menggambarkan bahwa sebagian besar perawat yang ada di RSUD Dr. M. Yunus Bengkulu memiliki nilai sikap negatif atau tidak mendukung. Ada 30 butir pertanyaan yang dibagikan kepada 63 perawat untuk mengukur sikap perawat terhadap perawatan paliatif dengan kuesioner The Frommelt's Attitude Toward Care of The Dying Care Form B (FATCOD-B) Versi Bahasa Indonesia. Adapun skala yang digunakan untuk mengukur sikap perawat terhadap perawatan paliatif yaitu Skala Likert. Nilai sikap diukur berdasarkan rumus T menurut Azwar (2011), dimana didapatkan nilai Positif jika skor $\mathrm{T}>$ nilai mean, sedangkan nilai Negatif jika skor $\mathrm{T}<$ nilai mean. Nilai Mean yang didapatkan dari data sebesar 378 sedangkan total T yang diperoleh sebesar 250. Hal ini dapat disimpulkan sebagian besar sikap perawat terhadap perawatan paliatif pada pasien yang ada di RSUD Dr. M. Yunus memiliki nilai sikap negatif atau tidak mendukung.

Hasil yang diperoleh dari identifikasi antara pengetahuan dan sikap sebanding dimana kedua-duanya masih kurang dalam melakukan perawatan paliatif. Hal ini sejalan dengan penelitian (Siagian \& Perangin-angin, 2020) yang menunjukan bahwa ada hubungan yang signifikan antara tingkat pengetahuan dan sikap perawat terhadap perawatan paliatif dengan nilai sig $0,011<0,05$. Dijelaskan juga dari hasil penelitian yang telah dilakukan oleh Yuke Kiran (2017), terbentuknya sikap positif dari perawat dapat dipengaruhi oleh interaksi antar sesama perawat, karena sikap terbentuk dengan interaksi terjadi saling tukar informasi mengenai hal yang berhubungan dengan pelaksanaan asuhan keperawatan, perawat mau memperhatikan kebutuhan klien, mengerjakan dan menyelesaikan yang diberikan serta mengajak orang lain untuk mengerjakan atau mendiskusikan suatu masalah. 
Hasil studi Grubb \& Arthur dalam (A'la, 2016), menyebutkan bahwa sikap yang positif dalam perawatan paliatif dapat menjadi tolak ukur keberhasilan mahasiswa keperawatan terhadap pasien menjelang ajal. Sikap perawat yang negatif, seperti perasaan tidak peduli, takut, dan cemas dalam setiap pemberian asuhan keperawatan dapat menurunkan kualitas pelayanan menjelang ajal pada pasien.Villar dalam Agustina M (2019) menyatakan bahwa sikap dalam perawatan sangat penting dalam peningkatan status derajat kesehatan pasien khususnya pasien menjelang ajal. Menurut Hafifah (2018), sikap dalam perawatan menjelang ajal dapat menjadikan tolak ukur efektifnya proses pembelajaran atau pelatihan. Indikator yang dimaksud adalah mencakup kognitif, afektif, dan psikomotor.

Berdasarkan beberapa pendapat di atas diperoleh hasil bahwa antara sikap dengan pengetahuan saling berhubungan. Sikap perawat terhadap perawatan paliatif yang saya teliti bernilai negatif atau tidak mendukung dimana nilai $\mathrm{T}$ lebih kecil dari Mean. Sikap menjadikan tolak ukur efektifnya proses pelayanan langsung dengan pasien. Sikap yang positif dalam perawatan paliatif dapat menjadi tolak ukur keberhasilan sedangkan sikap yang negatif juga akan mempengaruhi pasien. Sebaiknya kita sebagai seorang perawat harus mencerminkan sikap yang positif kepada pasien agar pasien yang kita rawat selalu merasa nyaman jika berada di dekat kita meningkatkan kualitas hidupnya serta dapat mempersiapkan kematian yang damai serta berkualitas.

\section{SIMPULAN DAN SARAN}

\section{SIMPULAN}

Berdasarkan hasil penelitian dapat disimpulkan; perawat dengan jenis kelamin perempuan lebih dominan daripada laki-laki yakni sebesar 65\%, pendidikan terakhir perawat $48 \%$ mayoritas adalah Ners, perawat yang diteliti 60,3\% rata-rata ber usia $\geq 35-50$. Lebih dari sebagian $(52 \%)$ responden memiliki pengetahuan yang masih kurang. Sebanyak 63 perawat memiliki sikap negatif terhadap perawatan paliatif di 4 ruangan RSUD Dr.M. Yunus Bengkulu. 


\section{SARAN}

Disarankan bagi rumah sakit diharapkan agar tetap selalu meningkatkan produktivitas perawat. Salah satunya adalah dengan cara mengadakan seminar atau pelatihan tentang perawatan paliatif. Bagi institusi pendidikan diharapkan dapat dilakukan pengembangan kurikulum serta kompetensi khususnya dalam bidang perawatan paliatif.

\section{DAFTAR RUJUKAN}

Anggi, dkk. 2017. Palliative Care Quiz for Nurses-Indonesian (PCQN - I): A crosscultural adaptation, validity, and reliability study. (Online). (https://www.researchsquare.com/article/rs-6876/v1.pdf diakses 25 September 2020)

Agustina M. 2019. Pengetahuan Dan Sikap Mahasiswa Keperawatan Tentang Keperawatan Paliatif Di Universitas Advent Indonesia. diakses 16 Agustus 2020)

(Online). (http://ejournal.unklab.ac.id/index.php/kjn

Ariani Putri K. 2018. Rumah Singgah Dalam Perawatan Paliatif . (Online). https://simdos.unud.ac.id/uploads/file_penelitian_1_dir/248bdfcdb51ab22eb d6b82572c13f876.pdf diakses 22 Agustus 2020)

Arikunto, Suharsimi. 2013. Prosedur Penelitian Suatu Pendekatan Praktik. Jakarta: Rineka Cipta.

Giarti \& Purwanti. 2018. Gambaran Pengetahuan Perawat Tentang Perawatan Paliatif Pada Pasien Kanker Di Rsud Dr. Moewardi. (Online). (http://eprints.ums.ac.id/60054/diakses tanggal 23 Maret 2021)

Hafifah, 2018. Pengalaman Keluarga Dalam Pengambilan Keputusan Pada Pasien Kritis Di Ruang Intensive Care Unit (Icu) Rsud Ulinbanjarmasin. (Online). (https://ppjp.ulm.ac.id/journal/index.php/JDK/article/view/4948 diakses 22 Agustus 2020)

Notoatmodjo. 2014. Metodologi Penelian Kesehatan. Jakarta : Rineka Cipta

Maulida, M. N, dkk. (2017). Gambaran Pengetahuan dan Sikap Perawat Mengenai Perawatan Paliatif. Proceeding Seminar Nasional Keperawatan. (Online). Vol. 3. (http://conference.unsri.ac.id/index.php/SNK/article/view/761/390 diakses tanggal 22 Agustus 2020)

Saryono. 2017. Metodologi Penelitian Kesehatan. Yogyakarta: Mitra Cendikia 
Saryono \& Anggraeni. 2017. Metodologi Penelitian Kualitatif dan Kuantitatif dalam Bidang Kesehatan. Yogyakarta: Nuhamedika

Siagian E \& Perangin-angin M. 2020. Pengetahuan dan Sikap Perawat tentang Perawatan Paliatif di Rumah Sakit. (Online). (http://journals.stikim.ac.id/index.php/jiiki/article/view/587 diakses tanggal 22 Maret 2021)

Sugiyono. 2016. Metode Penelitian Kuantitatif, Kualitatif dan R\&D. Bandung: Alfabeta

Sugiyono. 2018. Metode Penelitian Pendidikan. Bandung: Alfabeta Suhartini.2012. Pengetahuan dan Keterampilan Perawat Dalam Pelayanan Keperawatan Holistik di Indonesian Holistic Tourist Hospital. (Online). (http://ejournal-sl.undip.ac.id/index.php/jnursing diakses tanggal 22 Agustus 2020)

Utama Anggraini T. 2019. Dukungan Keluarga dalam Pemenuhan Kebutuhan Spiritual Pasien di Ruang ICU RSUD dr. M. Yunus Bengkulu. (Online). (http://ejournal.unib.ac.id/index.php/JurnalVokasiKeperawatan/article/vie w/10695 diakses tanggal 22 Agustus 2020)

Vironica. 2018. Perawatan Paliatif. (Online). (http://www.rscarolus.or.id/article/perawatan-paliatif diakses tanggal 22 Agustus 2020)

Wawan \& Dewi. 2019. Teori dan Pengukuran Pengetahuan, Sikap, dan Perilaku Manusia. Yogyakarta: Nuha Medika

Yodang. 2018. Buku Ajar Keperawatan Paliatif berdasarkan kurikulum AIPNI 2015. Jakarta: Trans Info Media.

Yuke Kiran. 2017. Pengetahuan dan Sikap Perawat dalam Memenuhi Kebutuhan Psikologis dan Spiritual Klien Terminal. (Online). (https://ejournal.upi.edu/index.php/JPKI/article/viewFile/9425/5801. diakses tanggal 16 Agustus 2020)

Zulfatul, 2016. Pengukuran Validitas pada Mahasiswa Keperawatan Menggunakan Analisis Faktor. (Online). (https://media.neliti.com/media/publications/197121-ID-the-frommeltattitudes-toward-care-of-th.pdf diakses tanggal 27 Agustus 2020 